\title{
Endoscopic ultrasound-guided renal biopsy: an alternative to transjugular renal biopsy in high-risk patients
}

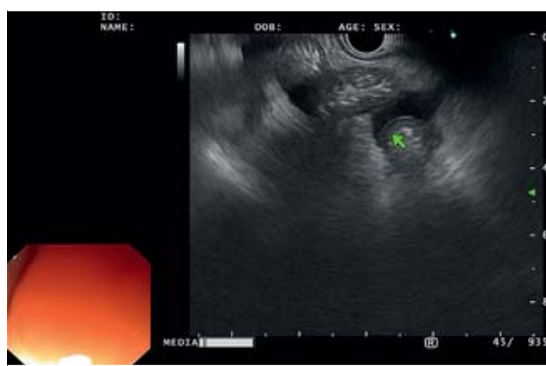

- Fig. 1 Endoscopic ultrasonography showing interbowel fluid.

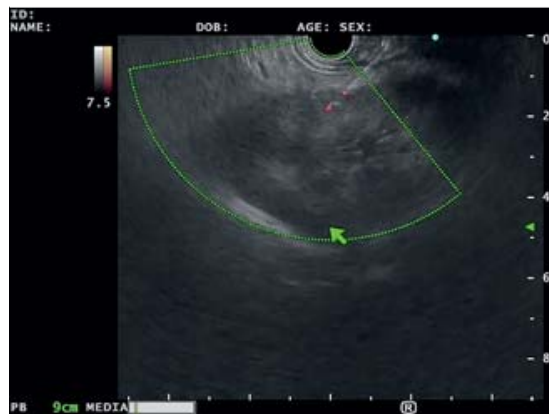

- Fig. 2 Endoscopic ultrasound-guided fine-needle biopsy (FNB) taken from lower pole of left kidney.

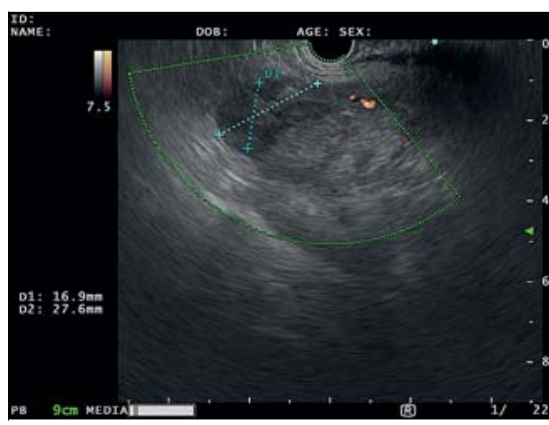

- Fig. 3 Subcapsular hematoma in the lower pole of the left kidney, $27 \times 17 \mathrm{~mm}$ in size.
A 32-year-old man with hepatocellular cancer who had undergone right hepatectomy 2 years previously presented with facial puffiness and abdominal distension. Ultrasound showed moderate ascites with normal kidneys. Serum albumin was $2.8 \mathrm{~g} / \mathrm{dL}$, hemoglobin $8.4 \mathrm{~g} / \mathrm{dL}$, platelet count $74000 / \mu \mathrm{L}$, and creatinine $1.7 \mathrm{mg} / \mathrm{dL}$. Urine examination showed $3+$ proteinuria and 3 +hematuria, while 24-hour urinary protein was $3030 \mathrm{mg} / \mathrm{dL}$. Transjugular renal biopsy (TJRB) was advised after nephrology consultation, due to the ascites with thrombocytopenia, but the patient was not willing to undergo this procedure. Hence, endoscopic ultrasound (EUS)-guided biopsy with a linear echoendoscope (GIF UCT180; Olympus, Tokyo, Japan) was planned.

Examination revealed significant ascites with interbowel fluid (>Fig. 1). The left kidney was sampled via a transgastric approach, as the patient's surgically altered anatomy made scope positioning in the duodenal bulb precarious. A 22G Acquire needle (Boston Scientific, USA) was used to target the cortex of the lower pole of the left kidney, avoiding major medullary vessels. Two passes were made with three actuations each, with a slow-stylet pull-through (>Fig.2; > Video 1). A $2.7 \times 1.6 \mathrm{~cm}$ subcapsular hematoma was seen ( $\triangleright$ Fig.3). On visualization up to 10 minutes, no increase in the size of the hematoma could be seen. Ultrasound 12 hours after the procedure still revealed no increase in the hematoma. A 20-mm core was sent for histopathologic analysis and immunofluorescence studies (> Fig.4). The diagnosis of focal segmental glomerulosclerosis was confirmed (> Fig.5).

TJRB is the alternative to percutaneous biopsy in high-risk patients with ascites and thrombocytopenia [1]. EUS-guided fine-needle aspiration cytology of renal masses has been described in case series $[2,3]$, but sampling for primary diagnosis

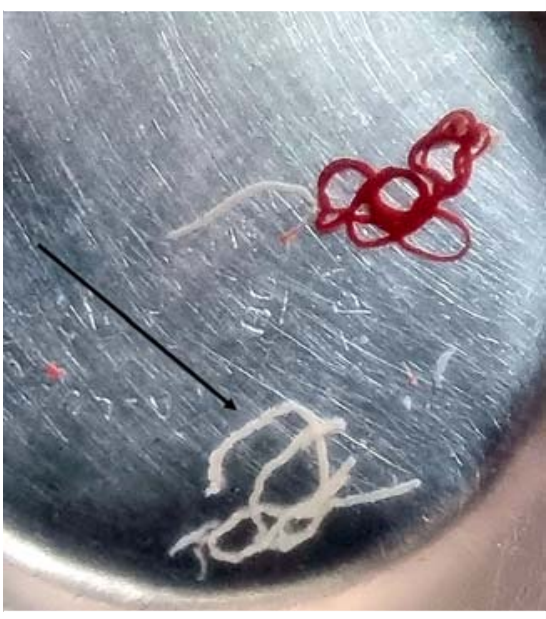

- Fig. 4 Core specimen (arrow) obtained with a 22G FNB needle.

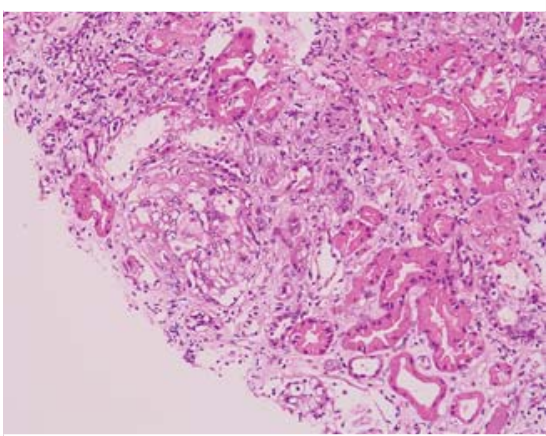

- Fig. 5 Histopathologic analysis revealed a sclerosed glomerulus with mesangial widening with fibrosis in the interstitium, suggestive of focal segmental glomerulosclerosis.

of nephrotic syndrome has not been described. Unlike in EUS liver biopsy, where a 196 needle is used [4], in our case a $22 \mathrm{G}$ needle was used to reduce risk of bleeding. We were able to achieve an optimal sample for diagnosis using EUS, while avoiding radiation exposure and the use of contrast in a patient with compromised renal function.

Endoscopy_UCTN_Code_CCL_1AF_2AF_3AD 


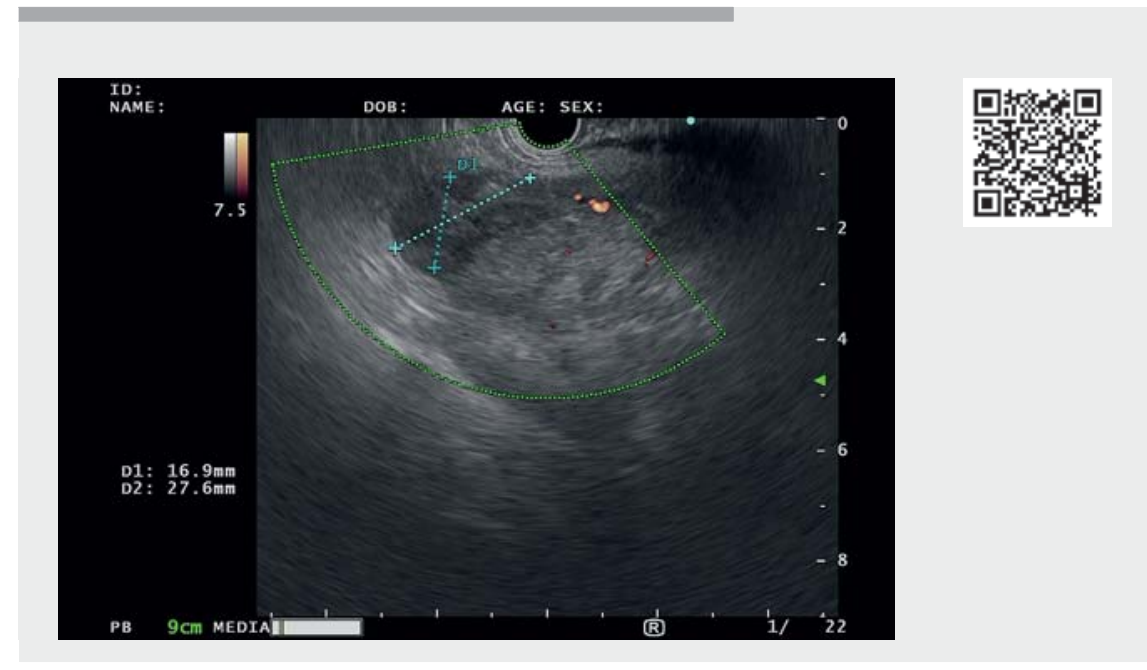

$\checkmark$ Video 1 Endoscopic ultrasound-guided kidney biopsy from the lower pole of the left kidney for evaluation of nephrotic syndrome.

\section{Competing interests}

The authors declare that they have no conflict of interest.

The authors

Sridhar Sundaram 1 , Prachi Patil', Aadish Jain' Utkarsh Chhanchure ${ }^{1}$, Suman Kumar Ankathi ${ }^{1}$, Shaila Khubchandani², Shaesta Mehta ${ }^{1}$

1 Department of Digestive Diseases and Clinical Nutrition, Tata Memorial Hospital, Mumbai, India

2 Department of Pathology, Jaslok Hospital, Mumbai, India the diagnosis of kidney lesions: a review. World J Gastrointest Endosc 2015; 7: 253257

[3] Law R, Wobker S, Grimm IS et al. Endoscopic ultrasonography-guided fine needle aspiration of kidney masses. Gastroenterology 2015; 148: 1282-1283

[4] Patel HK, Saxena R, Rush N et al. A comparative study of $22 \mathrm{G}$ versus $19 \mathrm{G}$ needles for EUS-guided biopsies for parenchymal liver disease: are thinner needles better? Dig Dis Sci 2021; 66: 238-246

\section{Bibliography}

Endoscopy 2022; 54: E285-E286

DOI 10.1055/a-1519-6365

ISSN 0013-726X

published online 2.7.2021

(c) 2021. Thieme. All rights reserved.

Georg Thieme Verlag KG, Rüdigerstraße 14, 70469 Stuttgart, Germany

\section{ENDOSCOPY E-VIDEOS}

https://eref.thieme.de/e-videos

\section{Sridhar Sundaram, MD, DM}

Department of Digestive Diseases and Clinical Nutrition, Tata Memorial Hospital, Dr. E. Borges Road, Parel, Mumbai, Maharashtra 400012, India drsridharsundaram@gmail.com

\section{References}

[1] Rathod KR, Popat BA, Pandey A et al. Safety and effectiveness of transjugular renal biopsy: a single center study. Indian J Nephrol 2017; 27: 118-123

[2] Lopes RI, Moura RN, Artifon E. Endoscopic ultrasound-guided fine-needle aspiration for 